Article

\title{
Paradigm Shift of Healthcare Cost for Patients with Inflammatory Bowel Diseases: A Claims Data-Based Analysis in Japan
}

\author{
Shota Saito ${ }^{1, *}$, Kyoko Nakazawa ${ }^{2}$, Kenji Suzuki ${ }^{1}$, Takashi Ishikawa ${ }^{3,4}$ and Kouhei Akazawa ${ }^{4}$ \\ 1 Department of Health Informatics, Niigata University of Health and Welfare, Niigata 950-3198, Japan; \\ kenji-suzuki@nuhw.ac.jp \\ 2 Department of Medical Informatics and Statistics, Niigata University Graduate School of Medical and \\ Dental Sciences, Niigata 951-8520, Japan; nakakyo-nii@umin.ac.jp \\ 3 Division of Digestive and General Surgery, Niigata University Graduate School of Medical and Dental \\ Sciences, Niigata 951-8520, Japan; takish@med.niigata-u.ac.jp \\ 4 Department of Medical Informatics, Niigata University Medical and Dental Hospital, Niigata 951-8520, \\ Japan; akazawa@med.niigata-u.ac.jp \\ * Correspondence: shota-saito@nuhw.ac.jp; Tel.: +81-25-257-4455
}

Received: 18 October 2018; Accepted: 8 November 2018; Published: 9 November 2018

\begin{abstract}
Anti-tumor necrosis factor- $\alpha$ (anti-TNF $\alpha$ ) agents are used for induction and maintenance of remission in patients with inflammatory bowel diseases (IBD). However, biologic drugs present a large economic burden on health insurance systems. We aimed to estimate the mean annual health care cost per patient with IBD and cost contribution of anti-TNF $\alpha$ agents. We performed an analysis of patients with Crohn's disease (CD) and ulcerative colitis (UC) based on a large-scale administrative claims database constructed by Japan Medical Data Center (JMDC) Co. Ltd., comprising inpatient, outpatient, and pharmacy claims data. We evaluated all claims from 1 April 2013 through 31 March 2016. Descriptive statistics were used to measure median health care costs paid per member per year (PMPY) and the relative cost contribution of anti-TNF $\alpha$ agents. A total 1405 patients with CD and 5771 with UC were included. Median costs PMPY were approximately six times higher for CD than UC (JPY 1,957,320 and JPY 278,760, respectively). Medication cost for anti-TNF $\alpha$ agents was the main cost driver, accounting for $59.9 \%$ and $17.8 \%$ of the total costs for CD and UC, respectively. In Japan, costs for anti-TNF $\alpha$ agents have resulted in drug costs exceeding inpatient costs for IBD. Optimized use of anti-TNF $\alpha$ agents and introduction of biosimilars for anti-TNF $\alpha$ agents can be expected to substantially reduce the health care costs of IBD.
\end{abstract}

Keywords: biosimilars; claims data; health care costs; inflammatory bowel diseases

\section{Introduction}

Inflammatory bowel diseases (IBD), comprising Crohn's disease (CD) and ulcerative colitis (UC), are characterized by chronic relapsing intestinal inflammation that may lead to severe complications and disability [1]. IBD negatively affect the patient's health-related quality of life and account for substantial costs to the health care system and society [2].

There is no curative therapy for IBD; most patients need continuous drug therapy and some require surgical intervention. Frolkis et al. [3] reported that the cumulative risk of surgery in CD is $47 \%$ at 10 years after diagnosis; in addition, approximately $5 \%$ of patients with UC will require colectomy within 1 year of diagnosis and $16 \%$ within 10 years. Therefore, not only achieving but also maintaining symptom-free remission and endoscopic healing are the primary targets of therapy for IBD. 
Over the last decade, the advent of biologic therapy has significantly improved the clinical management of IBD. Anti-tumor necrosis factor- $\alpha$ (anti-TNF $\alpha$ ) agents, such as infliximab and adalimumab, have been widely used for the induction and maintenance of remission in both $C D$ and UC [4]. These agents are monoclonal antibodies that block the pro-inflammatory cytokine TNF involved in the pathogenesis of IBD. Mao et al. [5] suggested that anti-TNF $\alpha$ agents were associated with a statistically significant and meaningful reduction in hospitalization (by $50 \%$ ) and surgery (by 33-77\%) for IBD. The introduction of biologic drugs in clinical practice is expected to improve the natural history of IBD.

Long-term maintenance of biologic therapy is required for IBD, and biologic drugs are more expensive than conventional drugs, which leads to a significant economic burden for the health insurance system in Japan [6]. Several studies have showed that the health care costs of IBD are mainly driven by the drug cost of anti-TNF $\alpha$ agents. However, the economic impact of biologics in the treatment of IBD in Japan has not been clearly analyzed [7-9]. We hypothesized that most IBD-related costs are allocated to the group of patients with IBD who are receiving biologic therapy in Japan.

The aim of this study was to estimate the mean annual health care cost per patient and the cost contribution of anti-TNF $\alpha$ agents among patients with IBD, using claims data from Japan.

\section{Results}

\subsection{Patient Summary}

Figure 1 shows a flowchart of the selection of patients for inclusion in this study. The JMDC claims database included data of 3,310,322 members during the study period. In the cohort, the number of patients diagnosed with CD or UC at least once were 1998 and 8186, respectively. We excluded 503 patients with CD and 2415 patients with UC from the cohort, according to the exclusion criteria. Therefore, in this study, we analyzed 1405 patients with CD, including 303 women (21.6\%) and 1102 men $(78.4 \%)$, and 5771 patients with UC, including 2134 (37.0\%) women and 3637 (63.0\%) men.

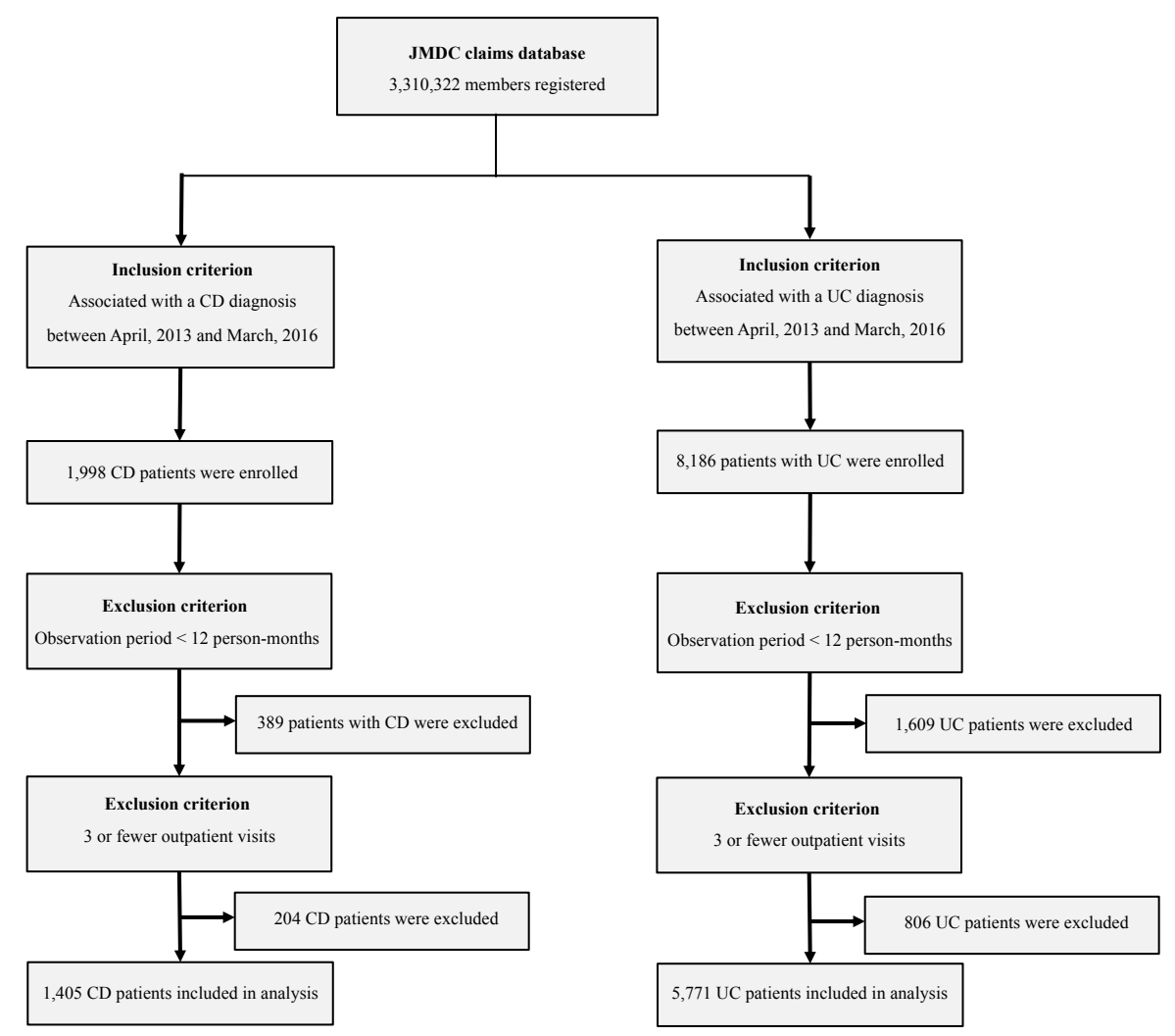

Figure 1. Flowchart for selection of patients with inflammatory bowel disease in this study. 


\subsection{Estimation of Health Care Costs and Use of Anti-TNFa Agents}

The median costs PMPY were JPY 1,957,320 (IQR 383,220-2,996,340) and JPY 278,760 (IQR 160,560-456,720) for CD and UC, respectively. These costs were approximately six times higher for CD than for UC. A total 55.2\% (95\% CI 52.6-57.8\%) of patients with CD and 7.5\% (95\% CI 6.9-8.2\%) of those with UC received biologic therapy. The patient subgroup aged 20-29 years for CD had the highest percentage of biologic therapy use $(67.0 \%)$. In contrast to $C D$, the highest percentage for $U C$ was only $20.0 \%$ in patients aged $10-19$ years (Tables 1 and 2 ).

Table 1. Median health care costs and use of biologic therapy for CD.

\begin{tabular}{|c|c|c|c|c|c|c|}
\hline \multirow{3}{*}{ Item } & \multirow{3}{*}{ Subgroup } & \multicolumn{5}{|c|}{ CD } \\
\hline & & \multirow{2}{*}{$n$} & \multirow{2}{*}{$\%$} & \multicolumn{2}{|c|}{ PMPY (JPY) } & \multirow{2}{*}{$\begin{array}{l}\text { Anti-TNF } \alpha \text { Agents } \\
\text { Used }(95 \% \text { CI })\end{array}$} \\
\hline & & & & Median & Interquartile Range & \\
\hline $\mathrm{N}$ & All & 1405 & & $1,957,320$ & $383,220-2,996,340$ & $0.552(0.526-0.578)$ \\
\hline \multirow{2}{*}{ By sex } & Woman & 303 & $21.6 \%$ & $1,446,480$ & $318,120-2,525,520$ & $0.502(0.446-0.558)$ \\
\hline & Man & 1102 & $78.4 \%$ & $2,053,680$ & $406,620-3,103,830$ & $0.566(0.537-0.595)$ \\
\hline \multirow{8}{*}{$\begin{array}{l}\text { By age group } \\
\text { (years) }\end{array}$} & $0-9$ & 6 & $0.4 \%$ & $1,129,380$ & $835,800-7,063,740$ & $0.167(0.030-0.563)$ \\
\hline & 10-19 & 82 & $5.8 \%$ & $2,292,240$ & $557,250-3,180,630$ & $0.634(0.526-0.730)$ \\
\hline & $20-29$ & 285 & $20.3 \%$ & $2,173,800$ & $697,860-3,071,940$ & $0.670(0.614-0.722)$ \\
\hline & $30-39$ & 389 & $27.7 \%$ & $2,056,080$ & $383,100-3,103,500$ & $0.584(0.534-0.631)$ \\
\hline & $40-49$ & 377 & $26.8 \%$ & $1,930,800$ & $363,840-3,105,480$ & $0.538(0.488-0.588)$ \\
\hline & $50-59$ & 207 & $14.7 \%$ & $1,341,720$ & $306,840-2,718,000$ & $0.440(0.374-0.508)$ \\
\hline & $60-69$ & 52 & $3.7 \%$ & 373,560 & $231,660-1,745,340$ & $0.216(0.122-0.340)$ \\
\hline & $70+$ & 7 & $0.5 \%$ & 161,040 & $69,240-293,640$ & 0 (NA) \\
\hline
\end{tabular}

Abbreviations: CI, Confidence interval; NA, not applicable; CD, Crohn disease; PMPY, per member per year; TNF $\alpha$, tumor necrosis factor alpha; JPY, Japanese yen. Anti-TNF $\alpha$ agents include infliximab and adalimumab. "N" means the all patients in $C D$ cohort.

Table 2. Median health care costs and use of biologic therapy for UC.

\begin{tabular}{|c|c|c|c|c|c|c|}
\hline \multirow{3}{*}{ Item } & \multirow{3}{*}{ Subgroup } & \multicolumn{5}{|c|}{ UC } \\
\hline & & \multirow{2}{*}{$n$} & \multirow{2}{*}{$\%$} & \multicolumn{2}{|c|}{ PMPY (JPY) } & \multirow{2}{*}{$\begin{array}{c}\text { Anti-TNF } \alpha \text { Agents } \\
\text { Used }(95 \% \text { CI })\end{array}$} \\
\hline & & & & Median & Interquartile Range & \\
\hline $\mathrm{N}$ & All & 5771 & & 278,760 & $160,560-456,720$ & $0.075(0.069-0.082)$ \\
\hline \multirow{2}{*}{ By sex } & Woman & 2134 & $37.0 \%$ & 279,240 & $158,820-460,620$ & $0.075(0.065-0.087)$ \\
\hline & Man & 3637 & $63.0 \%$ & 278,280 & $161,760-453,540$ & $0.075(0.067-0.084)$ \\
\hline \multirow{8}{*}{$\begin{array}{l}\text { By age group } \\
\text { (years) }\end{array}$} & $0-9$ & 12 & $0.2 \%$ & 903,240 & $293,040-4,186,050$ & $0.083(0.015-0.354)$ \\
\hline & 10-19 & 170 & $2.9 \%$ & 464,100 & $239,730-1,303,200$ & $0.200(0.147-0.266)$ \\
\hline & $20-29$ & 704 & $12.2 \%$ & 301,800 & $172,530-553,470$ & $0.117(0.095-0.142)$ \\
\hline & $30-39$ & 1324 & $22.9 \%$ & 271,560 & $158,220-443,670$ & $0.085(0.071-0.101)$ \\
\hline & $40-49$ & 1825 & $31.6 \%$ & 258,960 & $148,740-417,960$ & $0.066(0.055-0.078)$ \\
\hline & $50-59$ & 1237 & $21.4 \%$ & 276,120 & $163,920-434,220$ & $0.051(0.040-0.065)$ \\
\hline & $60-69$ & 440 & $7.6 \%$ & 291,900 & $162,630-504,990$ & $0.048(0.031-0.072)$ \\
\hline & $70+$ & 59 & $1.0 \%$ & 332,880 & $213,240-623,280$ & 0 (NA) \\
\hline
\end{tabular}

Abbreviations: CI, Confidence interval; NA, not applicable; UC, ulcerative colitis; PMPY, per member per year; $\mathrm{TNF} \alpha$, tumor necrosis factor alpha; JPY, Japanese yen. Anti-TNF $\alpha$ agents include infliximab and adalimumab. "N" means the all patients in UC cohort.

\subsection{Share of Drug Costs Associated with Anti-TNFa Agents in Healthcare Costs}

Figure 2 depicts the share of drug costs associated with infliximab and adalimumab, out of the overall health care costs for CD and UC over 3 years. The total cost related to CD and UC was estimated to be JPY 7,139,604,830 and JPY 7,488,918,470, respectively. The medication cost of anti-TNF $\alpha$ agents was the main cost driver, accounting for $59.5 \%$ and $17.8 \%$ of the entire cost for $\mathrm{CD}$ and UC, respectively. Notably, the drug cost of anti-TNF $\alpha$ agents alone comprised nearly four-fifths (78.7\%) of outpatient costs. The cumulative cost for inpatients was estimated to be approximately one-quarter and one-third that of outpatients for $\mathrm{CD}$ and $\mathrm{UC}$, respectively. 


\section{Crohn disease}

\section{Ulcerative colitis}

\section{Outpatients}

JPY 4,502,101,500 $7.2 \%$

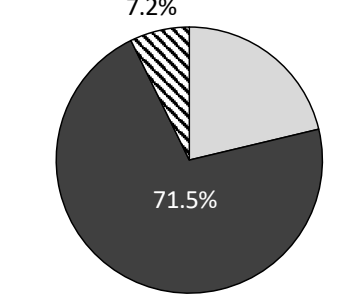

$\square$ Outpatient cost excluded anti-TNF $\alpha$ drugs - Infliximab

$\triangle$ Adalimumab

JPY $3,459,458,510$

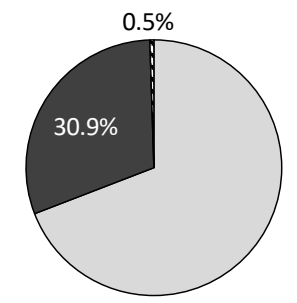

$\square$ Outpatient cost excluded anti-TNF $\alpha$ drugs 曰 Infliximab

ธ Adalimumab
Inpatients

JPY $1,157,538,640$

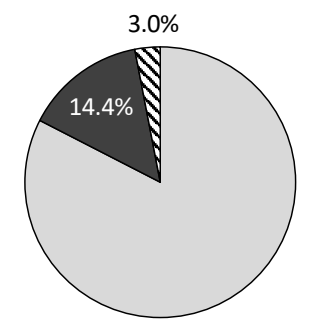

$\square$ Inpatient cost excluded anti-TNF $\alpha$ drugs - Infliximab

v Adalimumab

JPY 1,343,806,670

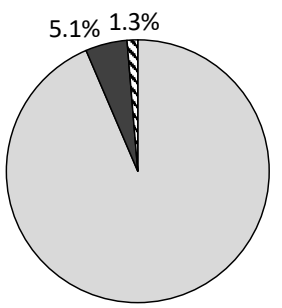

$\square$ Outpatient cost excluded anti-TNF $\alpha$ drugs $\square$ Infliximab

$\mathbf{\Delta}$ Adalimumab

\section{Pharmacy}

JPY 1,479,964,690

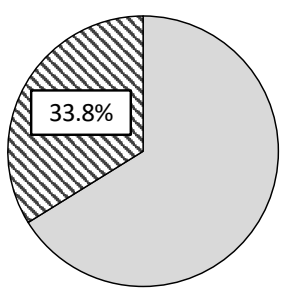

$\square$ Pharmacy cost excluded anti-TNF $\alpha$ drugs $\checkmark$ Adalimumab

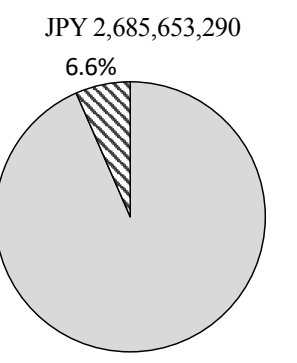

$\square$ Pharmacy cost excluded anti-TNF $\alpha$ drugs DAdalimumab

Figure 2. Proportion of drug costs associated with infliximab and adalimumab, out of overall healthcare costs.

\subsection{Number of Patients with IBD Who Received Biologics among PMPY Subgroups}

Table 3 shows the number of patients with CD and UC who received biologics and those who did not, for each subgroup of costs PMPY. Cochran-Armitage analysis showed that the proportion of anti-TNF $\alpha$ agent use was significantly increased among groups with higher costs PMPY, for both CD and UC $(p<0.001)$.

Table 3. Biologic therapy in patients with CD and UC, in subgroups by costs PMPY.

\begin{tabular}{|c|c|c|c|c|c|}
\hline \multicolumn{6}{|c|}{ PMPY Subgroup (JPY) } \\
\hline & $\begin{array}{l}\text { Minimal Subgroup } \\
<1 \text { Million }\end{array}$ & $\begin{array}{c}\text { Low Subgroup } 1 \\
\text { Million to } 2 \text { Million }\end{array}$ & $\begin{array}{l}\text { Moderate Subgroup } 2 \\
\text { Million to } 3 \text { Million }\end{array}$ & $\begin{array}{l}\text { High Subgroup } \\
>3 \text { Million }\end{array}$ & $p$-Value * \\
\hline \multicolumn{6}{|l|}{$\mathrm{CD}$} \\
\hline Biologics & 23 & 85 & 326 & 342 & \multirow{3}{*}{$<0.001$} \\
\hline No biologics & 533 & 68 & 19 & 9 & \\
\hline Total $(n=1405)$ & 556 & 153 & 345 & 351 & \\
\hline \multicolumn{6}{|l|}{ UC } \\
\hline Biologics & 46 & 115 & 165 & 107 & \multirow{3}{*}{$<0.001$} \\
\hline No biologics & 5060 & 190 & 60 & 28 & \\
\hline Total $(n=5771)$ & 5106 & 305 & 225 & 135 & \\
\hline
\end{tabular}

Abbreviations: CD, Crohn disease; UC, ulcerative colitis; PMPY, per member per year; JPY, Japanese yen. * $p$-values were calculated using Cochran-Armitage trend test. 


\section{Discussion}

Economic evaluation is used for decision-making processes such as drug pricing and promotion of generic drugs. The number of patients with IBD has been increasing during the previous decade in Japan. It is expected that the use of biologic drugs in these patients may result in a shift from higher costs for hospitalization and surgery to higher outpatient chemotherapy costs in this population. Therefore, accurate estimation of the economic burden of IBD is an important issue for Japanese health policy makers.

Health technology assessment is a form of economic evaluation that assesses the health outcome and costs of interventions designed to improve patient's health. It has been used to evaluate the cost-effectiveness of treatment strategies for IBD. A systematic review of cost-effectiveness studies for IBD concluded that whereas biologic agents improved patient outcomes, they incurred high costs and were therefore generally not cost-effective [10]. There have been no economic studies regarding the health care costs in Japan for the use of biologics in IBD.

Recently, economic studies from the United States (US) and the Netherlands identified drug costs related to anti-TNF $\alpha$ agents as one of the primary cost drivers in IBD, accounting for $64 \%$ and $31 \%$ of the total costs in CD and UC, respectively $[7,8]$. Those studies concluded that there is an apparent shift in cost profiles from surgery and hospitalization towards biologic therapy in IBD.

A health economic study in the US reported that the proportion of biologics used for CD and UC in 2015 was $44.8 \%$ and 16.7\%, respectively [11]. Our results showed that the rate for UC in Japan is equivalent to the US data, but the rate for CD in Japan is much higher than that reported in the US. Moreover, Park et al. [6] reported that the mean cost PMPY of CD in the US was USD 18,637 (JPY 1,971,795: USD 1 = JPY 105.8).

Anti-TNF $\alpha$ agents are one of the available clinical options for moderately to severely active CD and UC, according to the diagnosis and treatment guidelines for these diseases [12]. However, the early introduction of biologics as a first-line drug in a "top-down" approach has been accepted as a treatment strategy in patients with CD, to avoid disease progression and bowel damage. Our results might reflect the treatment strategy shift toward aggressive use of biologics for CD in Japan [13,14]. Therefore, our findings suggest that IBD-related costs in Japan have been increasing, as in Western countries, and there is a likelihood that the use of biologics will continue to increase for IBD in Japan.

Recently, biosimilars have shown promise in reducing costs, with initial research suggesting that these biologics enter the market at a cost up to 30\% lower than the original biologics [15]. Biosimilars of infliximab have been available for IBD since 2013 in Europe and since 2016 in the US. In Japan, biosimilars of infliximab have been approved for IBD therapy since 2014. However, there were only eight patients with IBD who received biosimilars in our claims data. Using this dataset, we estimate that approximately JPY 100 million in annual drug costs can be saved if more than half of currently used infliximab is replaced with biosimilars for IBD.

Several studies have estimated the budgetary impact of the introduction of biosimilars for infliximab in rheumatoid arthritis treatment. These studies have found that introduction of biosimilar infliximab lead to considerable drug cost savings for rheumatoid arthritis across European countries [16,17]. Our results suggest that replacing original biologic drugs with biosimilars can be expected to reduce the health care costs related to IBD in Japan. Moreover, alternative therapies such as corticosteroid and azathioprine therapy are needed to optimize the use of biologics in Japanese patients with IBD.

Future economic research into IBD management is needed, focusing on the indirect costs, i.e., nonmedical costs incurred by the patient owing to their disease, such as absence from work). IBD is often diagnosed around the age of 20 years; therefore, it affects patients during their peak productive years. Mahlich et al. [18] demonstrated that unemployment was four times higher among patients with IBD than in the general population of Japan. Long-term maintenance of remission with biologic therapy contributes to reducing the indirect costs owing to unemployment. However, there are no 
studies demonstrating the relationship between the introduction of biologics and a reduction of indirect costs in Japan.

The current study has several limitations. First, the JMDC database did not include any information about clinical status, such as the results of clinical examination or a physician's assessment of severity. Moreover, the inclusion criterion of the claims data used this study did not consider the clinical history of each patient prior to April 2013. Therefore, we could not identify the reason for the use of biologics and the length of time from diagnosis to commencement of biologic therapy. Additionally, we did not analyze specific cost profiles because of the complexity of the data in the JMDC database; we only estimated the burden of biologics using the price and amount used according to the records. Finally, the exclusion criteria led to a substantial number of patients being excluded in our analyses. The JMDC database included a considerable number of patients with IBD with no treatment history in their records. We considered that a substantial number of suspected cases were included in the dataset.

Recent studies based on claims data have showed a dramatic increase in IBD-related health care costs worldwide $[11,19,20]$. In Japan, most of the costs of biologics for IBD are paid by the government, without the need for prior approval and with no time limitation [21]. In the current environment, biologics face few barriers to use by physicians. The use of biologics should be tailored to patients with IBD who are likely to benefit, to reduce overuse of biologic drugs.

\section{Materials and Methods}

\subsection{Overview of Claims Data}

We performed a longitudinal retrospective cohort analysis of patients with IBD based on demographic data and a large-scale claims database constructed by the Japan Medical Data Center (JMDC) Co. Ltd., Tokyo, Japan [10]. This database is completely anonymized and includes approximately 3.2 million cumulative insured persons, mainly company employees and their family members. The JMDC database is an administrative database comprising inpatient, outpatient, and pharmacy claims data. In this study, we evaluated all claims data from 1 April 2013 through 31 March 2016.

\subsection{Patient Identification}

We extracted patients who had at least one health insurance claim associated with a CD or UC diagnosis, with clinical diagnoses coded using International Classification of Diseases 10th Revision (ICD-10) classification (K50 or K51) during the period of analysis. Patient age was determined by considering the age at the midpoint of the claims analysis (30 September 2014). Age groups were further stratified into deciles for the analysis. We excluded patients with IBD who had insurance records for less than 12 months, or fewer than 3 outpatient records, during the study period.

\subsection{Estimation of Reimbursement of Health Care Costs}

The total annual reimbursement cost for all health services rendered for each included patient's health care was equal to the sum of the paid amounts for that patient. All individual paid amounts were summed and divided by the number of person-months. This monthly estimate was then multiplied by 12, to obtain paid costs per member per year (PMPY). The median costs PMPY for patients with CD and UC were calculated by sex and by age group.

We calculated the proportion of the drug cost for infliximab and adalimumab, out of the total cost related to $C D$ and $U C$, and for outpatients, inpatients, and pharmacy, separately. To examine trends of the treatment rate for biologics, patients were stratified by costs PMPY, as follows: $<$ JPY 1 million, JPY 1-2 million, JPY 2-3 million, >JPY 3 million. 


\subsection{Statistical Analysis}

All statistical analyses were performed using JMP version 13 (SAS Institute, Cary, NC, USA). We calculated the median with interquartile range (IQR) for health care costs (JPY, PMPY) paid for IBD, and the proportion for use of anti-TNF $\alpha$ agents, with $95 \%$ confidence intervals (CIs), stratified by age and sex. In addition, we reported the share of costs for anti-TNF $\alpha$ agents out of the cumulative cost for inpatients, outpatients, and pharmacy. The Cochran-Armitage trend test was used to test for linearity in the use of anti-TNF $\alpha$ agents, by subgroups of costs PMPY. For hypothesis testing, a $p$-value of $<0.05$ was selected to represent statistical significance.

\subsection{Ethical Considerations}

This study was approved by the Ethics Review Committee of Niigata University of Health and Welfare for Research Involving Human Participants (No. 17812; 8 June 2017).

\section{Conclusions}

In conclusion, our investigation suggested that the economic burden of IBD in Japan is significantly owing to the use of biologics, and that the treatment paradigm for $\mathrm{CD}$ is rapidly shifting to a top-down approach using anti-TNF $\alpha$ agents in the country. Optimization of the use of anti-TNF $\alpha$ agents and the introduction of biosimilars for anti-TNF $\alpha$ agents can be expected to substantially reduce health care costs related to IBD. Future research into IBD is needed, to optimize the use of value-based anti-TNF $\alpha$ agents and for accurate price revision based on cost-effectiveness analyses, in the era of biologics in Japan.

Author Contributions: Conceptualization, S.S., K.A.; Project Administration, K.A.; Data Curation, S.S., K.N.; Methodology and Formal Analysis, S.S., K.S., T.I.; Writing-Original Draft Preparation, S.S.; Writing-Review \& Editing, all authors.

Funding: This work was supported by a Grant-in-Aid for Exploratory Research from the Niigata University of Health and Welfare, 2017 (grant number H29B09), and the Japan Society for the Promotion of Science KAKENHI (grant number 16K08889).

Acknowledgments: We thank the Japan Medical Data Center Co., Ltd. for providing the claims database information. We also thank Analisa Avila, ELS, of Edanz Group (www.edanzediting.com/ac) for editing a draft of this manuscript.

Conflicts of Interest: The authors declare no conflict of interest.

\section{References}

1. Matsuoka, K.; Kobayashi, T.; Ueno, F.; Matsui, T.; Hirai, F.; Inoue, N.; Kato, J.; Kobayashi, K.; Kobayashi, K.; Koganei, K.; et al. Evidence-based clinical practice guidelines for inflammatory bowel disease. J. Gastroenterol. 2018, 53, 305-353. [CrossRef] [PubMed]

2. Ueno, F.; Nakayama, Y.; Hagiwara, E.; Kurimoto, S.; Hibi, T. Impact of inflammatory bowel disease on Japanese patients' quality of life: Results of a patient questionnaire survey. J. Gastroenterol. 2017, 52, 555-567. [CrossRef] [PubMed]

3. Frolkis, A.D.; Dykeman, J.; Negrón, M.E.; deBruyn, J.; Jette, N.; Fiest, K.M.; Frolkis, T.; Barkema, H.W.; Rioux, K.P.; Panaccione, R.; et al. Risk of surgery for inflammatory bowel diseases has decreased over time: A systematic review and meta-analysis of population-based studies. Gastroenterology 2013, 145, 996-1006. [CrossRef] [PubMed]

4. Di Sario, A.; Bendia, E.; Schiadà, L.; Sassaroli, P.; Benedetti, A. Biologic Drugs in Crohn's Disease and Ulcerative Colitis: Safety Profile. Curr. Drug Saf. 2016, 11, 55-61. [CrossRef] [PubMed] 
5. Mao, E.J.; Hazlewood, G.S.; Kaplan, G.G.; Peyrin-Biroulet, L.; Ananthakrishnan, A.N. Systematic review with meta-analysis: Comparative efficacy of immunosuppressants and biologics for reducing hospitalisation and surgery in Crohn's disease and ulcerative colitis. Aliment. Pharmacol. Ther. 2017, 45, 3-13. [CrossRef] [PubMed]

6. Park, K.T.; Colletti, R.B.; Rubin, D.T.; Sharma, B.K.; Thompson, A.; Krueger, A. Health Insurance Paid Costs and Drivers of Costs for Patients with Crohn's Disease in the United States. Am. J. Gastroenterol. 2016, 111, 15-23. [CrossRef] [PubMed]

7. Van der Valk, M.E.; Mangen, M.-J.J.; Leenders, M.; Dijkstra, G.; van Bodegraven, A.A.; Fidder, H.H.; de Jong, D.J.; Pierik, M.; van der Woude, C.J.; Romberg-Camps, M.J.L.; et al. COIN study group and the Dutch Initiative on Crohn and Colitis. Healthcare costs of inflammatory bowel disease have shifted from hospitalisation and surgery towards anti-TNF $\alpha$ therapy: Results from the COIN study. Gut 2014, 63, 72-79. [CrossRef] [PubMed]

8. Niewiadomski, O.; Studd, C.; Hair, C.; Wilson, J.; McNeill, J.; Knight, R.; Prewett, E.; Dabkowski, P.; Dowling, D.; Alexander, S.; et al. Health Care Cost Analysis in a Population-based Inception Cohort of Inflammatory Bowel Disease Patients in the First Year of Diagnosis. J. Crohns Colitis 2015, 9, 988-996. [CrossRef] [PubMed]

9. Kimura, S.; Sato, T.; Ikeda, S.; Noda, M.T.; Nakayama, T. Development of a database of health insurance claims: Standardization of disease classifications and anonymous record linkage. J. Epidemiol. 2010, 20, 413-419. [CrossRef] [PubMed]

10. Pillai, N.; Dusheiko, M.; Burnand, B.; Pittet, V. A systematic review of cost-effectiveness studies comparing conventional, biological and surgical interventions for inflammatory bowel disease. PLOS ONE 2017, 12, e0185500. [CrossRef] [PubMed]

11. Yu, H.; MacIsaac, D.; Wong, J.J.; Sellers, Z.M.; Wren, A.A.; Bensen, R.; Kin, C.; Park, K.T. Market share and costs of biologic therapies for inflammatory bowel disease in the USA. Aliment. Pharmacol. Ther. 2018, 47, 364-370. [CrossRef] [PubMed]

12. The Japanese Society of Gastroenterology. Clinical Practice Guideline for Inflammatory Bowel Disease; Nankodo: Tokyo, Japan, 2016. (In Japanese)

13. Blonski, W.; Buchner, A.M.; Lichtenstein, G.R. Inflammatory bowel disease therapy: Current state-of-the-art. Curr. Opin. Gastroenterol. 2011, 27, 346-357. [CrossRef] [PubMed]

14. Amezaga, A.J.; Van Assche, G. Practical Approaches to “Top-Down” Therapies for Crohn's Disease. Curr. Gastroenterol. Rep. 2016, 18, 35. [CrossRef] [PubMed]

15. Danese, S.; Bonovas, S.; Peyrin-Biroulet, L. Biosimilars in IBD: From theory to practice. Nat. Rev. Gastroenterol. Hepatol. 2017, 14, 22-31. [CrossRef] [PubMed]

16. Brodszky, V.; Baji, P.; Balogh, O.; Péntek, M. Budget impact analysis of biosimilar infliximab (CT-P13) for the treatment of rheumatoid arthritis in six Central and Eastern European countries. Eur. J. Health Econ. 2014, 15, 65-71. [CrossRef] [PubMed]

17. Jha, A.; Upton, A.; Dunlop, W.C.; Akehurst, R. The Budget Impact of Biosimilar Infliximab (Remsima ${ }^{\circledR}$ ) for the Treatment of Autoimmune Diseases in Five European Countries. Adv. Ther. 2015, 32, 742-756. [CrossRef] [PubMed]

18. Mahlich, J.; Matsuoka, K.; Nakamura, Y.; Sruamsiri, R. The relationship between socio-demographic factors, health status, treatment type, and employment outcome in patients with inflammatory bowel disease in Japan. BMC Public Health 2017, 7, 623. [CrossRef] [PubMed]

19. Bähler, C.; Vavricka, S.R.; Schoepfer, A.M.; Brüngger, B.; Reich, O. Trends in prevalence, mortality, health care utilization and health care costs of Swiss IBD patients: A claims data based study of the years 2010, 2012 and 2014. BMC Gastroenterol. 2017, 17, 138. [CrossRef] [PubMed] 
20. Kim, J.W.; Lee, C.K.; Rhee, S.Y.; Oh, C.H.; Shim, J.-J.; Kim, H.J. Trends in health-care costs and utilization for inflammatory bowel disease from 2010 to 2014 in Korea: A nationwide population-based study. J. Gastroenterol. Hepatol. 2018, 33, 847-854. [CrossRef] [PubMed]

21. Wei, S.C. Differences in the public medical insurance systems for inflammatory bowel disease treatment in Asian countries. Intest. Res. 2016, 14, 218-223. [CrossRef] [PubMed] 